\title{
Wogonoside inhibits cell growth and induces mitochondrial-mediated autophagy-related apoptosis in human colon cancer cells through the PI3K/AKT/mTOR/p70S6K signaling pathway
}

\author{
CHENGZHENG HAN ${ }^{1}$, GUOZHENG XING ${ }^{2}$, MENGYING ZHANG ${ }^{3}$, \\ MIN ZHONG ${ }^{3}, \mathrm{ZHEN} \mathrm{HAN}^{4}$, CHIYI HE ${ }^{4}$ and XIAOPING $\mathrm{LIU}^{5}$

\begin{abstract}
${ }^{1}$ Clinic of Integrated Traditional Chinese and Western Medicine, The First Affiliated Hospital of Wannan Medical College, Wuhu, Anhui 241001; ${ }^{2}$ School of Management, Science and Engineering, Anhui University of Technology, Ma'anshan, Anhui 243032; Departments of ${ }^{3}$ Central Laboratory and ${ }^{4}$ Gastroenterology, Wannan Medical College, Wuhu, Anhui 241001, P.R. China
\end{abstract} \\ The First Affiliated Hospital of Wannan Medical College; ${ }^{5}$ College of Pharmacy,
}

Received September 5, 2016; Accepted September 22, 2017

DOI: $10.3892 / \mathrm{ol} .2018 .7852$

\begin{abstract}
Wogonoside, the main effective constituent of traditional Chinese medicine Scutellaria, belongs to the glucuronide family, with various functions, including detoxification, anti-inflammation and nourishing gallbladder, lowering blood pressure, diuresis and anti-allergic reactions. However, the effects of wogonoside on human colon cancer cells remain unclear. The present study aimed to investigate the anticancer effect of wogonoside on human colon cancer cells in vitro and its anticancer mechanisms. The results demonstrated that wogonoside significantly inhibited cell growth, induced apoptosis and mitochondrial-mediated autophagy of colon cancer cells. Furthermore, the results revealed that wogonoside significantly increased caspase- 3 and caspase- 9 expression levels, induced apoptosis regulator Bax/Bcl-2 and microtubule-associated protein 1A/1B-light chain 3 protein expression, suppressed the phosphatidylinositol 3 kinase $(\mathrm{PI} 3 \mathrm{~K}) / \mathrm{RAC}-\alpha$ serine/threonine-protein kinase (Akt)/mechanistic target of rapamycin (mTOR)/p70 S6 kinase (p70S6K) signaling pathway and induced $\mathrm{p} 62$ protein expression in colon cancer cells. In conclusion, these results demonstrated that wogonoside inhibits cell growth and induces mitochondrial mediated autophagy-related apoptosis in human colon cancer
\end{abstract}

Correspondence to: Mr. Guozheng Xing, School of Management, Science and Engineering, Anhui University of Technology, 59 Hudong Road, Ma'anshan, Anhui 243032, P.R. China

E-mail: hlhugzaea8711@126.com

Key words: wogonoside, human colon cancer cells, phosphatidylinositol 3 kinase, $\mathrm{RAC}-\alpha$ serine/threonine-protein kinase, mechanistic target of rapamycin, p70 S6 kinase cells through modulation of the PI3K/Akt/mTOR/p70S6K signaling pathway.

\section{Introduction}

Colon cancer refers to the malignant lesions of colonic epithelium due to various environmental or genetic carcinogenic factors, ranking third most common among gastrointestinal tumors and also one of the most common malignant tumors (1). The majority of colon cancers is sporadic, and caused by risk factors, including aging, sex, environmental factors, obesity, diabetes, high fat diet, sitting for prolonged durations, insufficient intake of cellulose, smoking and drinking (2). Patients with intestine inflammatory diseases also possess a high risk of developing colon cancer, accounting for over two thirds of colon cancer cases. Furthermore, the risk of colon cancer is significantly associated with illness duration (2\% within 10 years vs. $18 \%$ within 30 years) and the severity of inflammatory diseases (3). Similar with other cancer types, the cause of colon cancer remains unknown. Studies have reported that the incidence and development of colon cancer involve multiple stages, and is caused by numerous factors $(2,4)$. In the last 20 years, it has been demonstrated that colon cancer is associated with environmental factors, diet, lifestyle and genetic factors (2). Carcinogens combined with genetic factors may lead to cell mutations and thereby gradually cause cancer.

Autophagy refers to the process of transporting substrates to lysosomes, which are then degraded and digested by lysosomal enzymes (5). It is an important way to degrade unnecessary proteins in eukaryotic cells, and is essential to the maintenance of homeostasis, growth, differentiation, development and environmental adaptability of cells (6). If the process of autophagy is disturbed, and large protein molecules with abnormal structures and damaged organelles cannot be removed, they accumulate in cells, affecting the normal development of cells, thus leading to various acute and chronic 
diseases, including cancer, neurodegenerative disease and myopathy as well as aging (7).

Microtubule-associated protein 1A/1B-light chain 3 (LC3), a homology of the yeast ATG8 (Aut7/Apg8) gene in mammalian cells, serves functions in the late stage of autophagosome formation, namely the extension of the pre-autophagosome structure (8). There are three subtypes of LC3 in mammalian cells, LC3A, LC3B and LC3C, and each subtype may be subdivided into type I and type II, among which only LC3B is associated with autophagy (8). Pro-LC3 is not processed in cells and is cleaved by Atg4 to form cytoplasmic LC3I. Following cleavage and ubiquitination, LC3I is evenly distributed in the cytoplasm and binds to phosphatidyl ethanolamine on the vesicle membrane of autophagosomes to form LC3-II, which has membrane binding capacity (9). LC3-II is located in the membrane of autophagosomes and pro- autophagosomes, when autophagy is activated, LC3-II increases with the increase in autophagosomes in cells (9). As LC3-II is located on the somatic membrane of autophagosomes, the concentration of LC3-II is considered to be directly proportional to the number of autophagosomes (10). Western blotting is used to detect the ratio of LC3 II/LC3I gray level, which quantitatively assesses the number of autophagosomes, and thus may be used as an effective index to detect the activity of autophagy (10).

Phosphatidylinositol 3 kinase (PI3K), a type of esterase that is activated when cells are stimulated by growth factors and other stimulatory factors, and its substrate 3,4-diphosphate phosphatidyl inositol is phosphorylated into 3,4,5-triphosphate phosphatidyl inositol (11). PI3K passes a mitotic signal to P70S6K1 via RAC- $\alpha$ serine/threonine-protein kinase (Akt) and mechanistic target of rapamycin (mTOR), to upregulate the translation of major proteins, including cyclin, and promote the progression of G1, so as to prolong cell cycle (11). In a previous study on colon and prostate cancer, it was demonstrated that inhibiting the activity of PI3K may significantly reduce the expression of CyclinD1 and cell cycle dependent protein kinase 4 (CDK4), as well as the phosphorylation of $\mathrm{Rb}$ (11). In addition, $\mathrm{PI} 3 \mathrm{~K}$ inhibition induced CDKs to suppress the expression of p21CIP1, blocking the G1 stage and thereby stopping cell cycle progression (11).

Cellular autophagy is a relatively conservative subcellular metabolism pathway in eukaryotes, and its underlying molecular mechanism is complex and highly conservative (12). The mTOR-dependent pathway, namely the PI3K/Akt/mTOR signaling pathway and its associated factors regulate cell autophagy (13). The transduction pathway stimulates upstream stimulatory factors, including various nutrients and growth factors to integrate. It then activates a series of downstream effectors to regulate a large number of activities, serving a key role in regulating cell proliferation, growth and differentiation. PI3K and its downstream molecule Akt constitute a signaling pathway, which reduces apoptosis, promotes the survival of cells and activates downstream mTOR to regulate autophagy (13). At present, numerous studies on the association between the PI3K/Akt/mTOR signaling pathway and autophagy have occurred, confirming that is serves important roles in regulating autophagy (14).

Scutellaria is a famous traditional Chinese medicine in China, with wogonoside and neobaicalein as its specific constituents (15). The former is a yellow crystal without an obvious melting point (15). It turns to red brown color when heated to $230^{\circ} \mathrm{C}$ and decomposes at $302^{\circ} \mathrm{C}$. In recent years, there has been increasing international studies on wogonoside leading to a more profound understanding of its effects, Scutellaria exhibits anti-oxidation, free radical removal and anti-tumor effects (16). It effectively inhibits the activity of hepatocellular carcinoma cells, colorectal cancer cells, cervical cancer cells, breast cancer cells and other tumor cells (17). In recent years, the study of the molecular mechanism of traditional Chinese medicine and its effective constituents in inhibiting tumors have made a lot of progress, resulting in various findings, including the inhibition of tumor growth by inducing cell apoptosis, cell toxicity, regulating cell signal transduction, inducing cell differentiation, reversing multidrug resistance and suppressing the activity of telomerase (16-18). In the present study, the potential anticancer effect of wogonoside on human colon cancer cells was demonstrated.

\section{Materials and methods}

Cell culture. Human colon cancer cells LOVO cells were cultured in Dulbecco's modified Eagle's medium supplemented with $10 \%$ fetal bovine serum (both from Thermo Fisher Scientific, Inc., Waltham, MA, USA) at $37^{\circ} \mathrm{C}$ with $5 \% \mathrm{CO}_{2}$. Wogonoside was purchased from Shanghai Tauto Biotech Co., Ltd. (Shanghai, China) and its structural formula is presented in Fig. 1.

Cell viability assays. LOVO cells ( $2 \times 10^{4}$ cells/well) were seeded into 96-well culture plates and cultured for $12 \mathrm{~h}$. Wogonoside $(0.00,1.95,3.91,7.81,15.63,31.25,62.50,125.00$, $250.00,500.00$ and $1,000.00 \mu \mathrm{M}$; control group is $0.00 \mu \mathrm{M}$ of wogonoside) was added to the cells and the cells were cultured for a further 24,48 or $72 \mathrm{~h}$. Cell viability was assessed using a cell counting kit-8 (CCK-8) assay (Beyotime Institute of Biotechnology, Shanghai, China). Following treatment with wogonoside, $10 \mu \mathrm{l}$ of CCK- 8 was added to cells and incubated for $30 \mathrm{~min}$. Absorbance value was read using a microplate reader (Multiskan MK3; Bio-Rad Laboratories, Inc., Hercules, CA, USA) at $450 \mathrm{~nm}$.

Flow cytometry analysis. LOVO cells $\left(1 \times 10^{6}\right.$ cells/well) were seeded into 96-well culture plates and cultured for $12 \mathrm{~h}$. Wogonoside was added to the cells and the cells were cultured for a further $48 \mathrm{~h}$, collected by trypsinization and washed twice with PBS. Cells were collected via centrifugation at $1,000 \mathrm{x} \mathrm{g}$ for $5 \mathrm{~min}$ at room temperature, and stained with Annexin V and propidium iodide (BD Biosciences, San Jose, CA, USA) for $30 \mathrm{~min}$ at room temperature in the dark. Cell apoptosis was measured using a FACScan laser flow cytometer (FACSCalibur; BD Biosciences) and analyzed using Image Lab 3.0 (Bio-Rad Laboratories, Inc.).

Immunofluorescence. Cells ( $1 \times 10^{6}$ cells/well) were seeded into 96-well culture plates and cultured for 12 days. Wogonoside was added to the cells and the cells were cultured for an additional $48 \mathrm{~h}$ at $37^{\circ} \mathrm{C}$ with $5 \% \mathrm{CO}_{2}$ and washed with PBS 3 times for $5 \mathrm{~min}$. Cells were fixed with $4 \%$ paraformaldehyde for $15 \mathrm{~min}$ at room temperature and blocked with 5\% BSA-TBST for $1 \mathrm{~h}$ at room temperature. Cells were incubated with LC3 


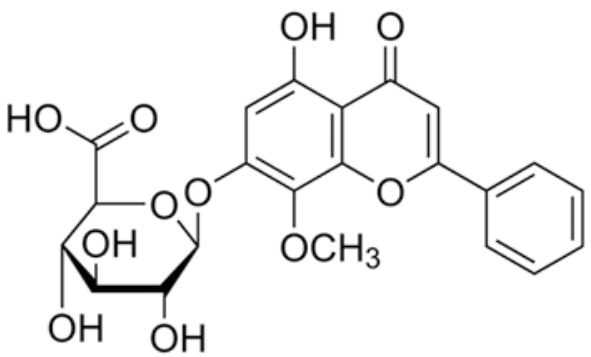

Figure 1. Chemical structure of wogonoside.

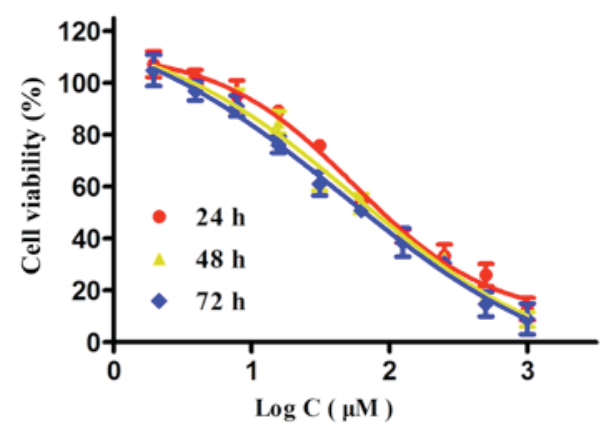

Figure 2. Wogonoside inhibits cell growth of LOVO colon cancer cells, as demonstrated by cell viability assays.

(cat.no. 12741; 1:100; Cell Signaling Technology, Inc., Danvers, MA, USA) at $4^{\circ} \mathrm{C}$ overnight and washed with PBST for $15 \mathrm{~min}$. Cells were incubated with 488 -conjugated anti-rabbit secondary antibodies for $1 \mathrm{~h}$ at $37^{\circ} \mathrm{C}$ and observed using a fluorescence microscope at magnification, x10 equipped with a CoolSNAP-Pro color digital camera (Media Cybernetics, Rockville, MD, USA).

Western blotting. LOVO cells $\left(1 \times 10^{6}\right.$ cells/well) were seeded into 96-well culture plates and cultured for 12 days. Wogonoside was added to the cells and the cells were cultured for a further $48 \mathrm{~h}$, collected by trypsinization and lysed in lysis buffer (Beyotime Institute of Biotechnology) at $4^{\circ} \mathrm{C}$ for $30 \mathrm{~min}$. Miscible liquids were elucidated by centrifugation at $10,000 \mathrm{x} \mathrm{g}$ for $15 \mathrm{~min}$ at $4^{\circ} \mathrm{C}$. The protein concentration was measured using a bicinchoninic acid assay (Beyotime Institute of Biotechnology). A total of $50 \mu \mathrm{g}$ protein/lane was separated by 10 or $12 \%$ SDS-PAGE and transferred onto polyvinylidene fluoride membranes (EMD Millipore, Billerica, MA, USA). Membranes were blocked with 5\% not-fat milk for $1 \mathrm{~h}$ at $37^{\circ} \mathrm{C}$ and incubated with the following primary antibodies: Caspase-3 (cat. no. 9665; 1:1,000 dilution), caspase-9 (cat. no. 9508; 1:1,000 dilution), apoptosis regulator Bax (Bax; cat. no. 14796; 1:1,000 dilution), apoptosis regulator Bcl-2 (Bcl-2; cat. no. 3498; 1:1,000 dilution), LC3 (cat. no. 13118; 1:2,000 dilution), PI3K (cat. no. 4249; 1:1,000 dilution), AKT (cat. no. 4685; 1:1,000 dilution), p-AKT (cat. no. 4060; 1:2,000 dilution), p-mTOR (cat. no. 5536; 1:1,000 dilution), p-p70 S6 kinase (p70S6K; cat. no. 9204; 1:2,000 dilution), p62 (cat. no. 23214; 1:2,000 dilution; all from Cell Signaling Technology) and GAPDH (cat. no. AF1186; 1:5,000 dilution; Beyotime Institute of Biotechnology) overnight at $4^{\circ} \mathrm{C}$ followed anti-rabbit horseradish peroxidase-conjugated secondary antibodies (cat. no. 7074; 1:5,000; Cell Signaling Technology, Inc.) for $1 \mathrm{~h}$ at $37^{\circ} \mathrm{C}$. Bands were detected using an enhanced chemiluminescence western blot detection kit (GE Healthcare, Chicago, IL, USA) and analyzed using Image Pro Plus software (version 3.0; Media Cybernetics, Inc., Rockville, MD, USA).

Statistical analysis. All data are presented as the mean \pm standard deviation using SPSS 20.0 (IBM Corp, Armonk, NY, USA). The statistical significance of the differences between treatments was assessed using one-way analysis of variance followed by Student-Newman-Keuls test for multiple comparisons. $\mathrm{P}<0.05$ was considered to indicate a statistically significant difference.

\section{Results}

Wogonoside inhibits the growth of colon cancer cells. To investigate the anticancer effect of wogonoside on the viability of colon cancer cells, LOVO cells were treated with different concentrations of wogonoside for 24, 48 and $72 \mathrm{~h}$. As presented in Fig. 2, wogonoside suppressed the viability of LOVO cells in a dose- and time-dependent manner, compared with the control group.

Wogonoside induces apoptosis in colon cancer cells. To evaluate the effect of wogonoside on the death of colon cancer cells, LOVO cells were treated with different concentrations of wogonoside for $48 \mathrm{~h}$. It was demonstrated that wogonoside significantly induced cell apoptosis in LOVO cells in a dose-dependent manner, compared with the control group (Fig. 3).

Wogonoside induces caspase-3 and caspase-9 protein expression in colon cancer cells. To evaluate the effect of wogonoside on the apoptotic mechanisms in colon cancer cells, caspase-3 and caspase- 9 protein expression were detected in LOVO cells following wogonoside treatment. As presented in Fig. 4, wogonoside $(31.25$ or $62.50 \mu \mathrm{M})$ significantly increased caspase-3 and caspase-9 protein expression in LOVO cells, compared with the control group.

Wogonoside induces Bax/Bcl-2 protein expression in colon cancer cells. Whether $\mathrm{Bax} / \mathrm{Bcl}-2$ participates in the anticancer effect of wogonoside was further investigated. Wogonoside (31.25 or $62.50 \mu \mathrm{M}$ ) significantly increased the Bax/Bcl-2 protein expression ratio in LOVO cells, compared with the control group (Fig. 5).

Wogonoside induces mitochondrial autophagy in colon cancer cells. To examine the effect of wogonoside on mitochondrial autophagy in colon cancer cells, LOVO cells were treated with different concentrations of wogonoside for $48 \mathrm{~h}$. Fig. 6 demonstrates that wogonoside markedly induced mitochondrial autophagy (LC3 protein expression) of LOVO cells in a dose-dependent manner, compared with the control group.

Wogonoside induces LC 3 protein expression in colon cancer cells. Next, the effect the mechanism of wogonoside on autophagy in colon cancer cell was examined, LC3 protein expression was measured following treatment of LOVO 


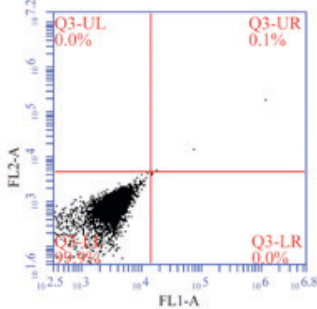

Control

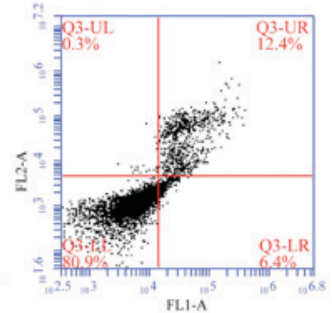

$15.63 \mu \mathrm{M}$

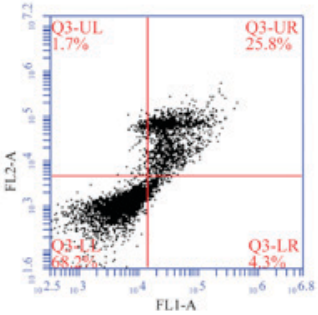

$31.25 \mu \mathrm{M}$

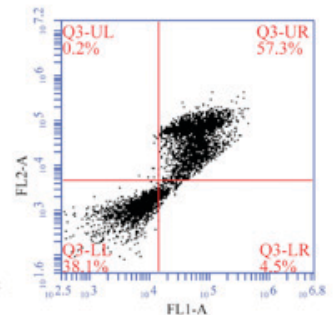

$62.50 \mu \mathrm{M}$

Figure 3. Wogonoside induces cell apoptosis of LOVO colon cancer cells, as demonstrated by flow cytometry analysis.

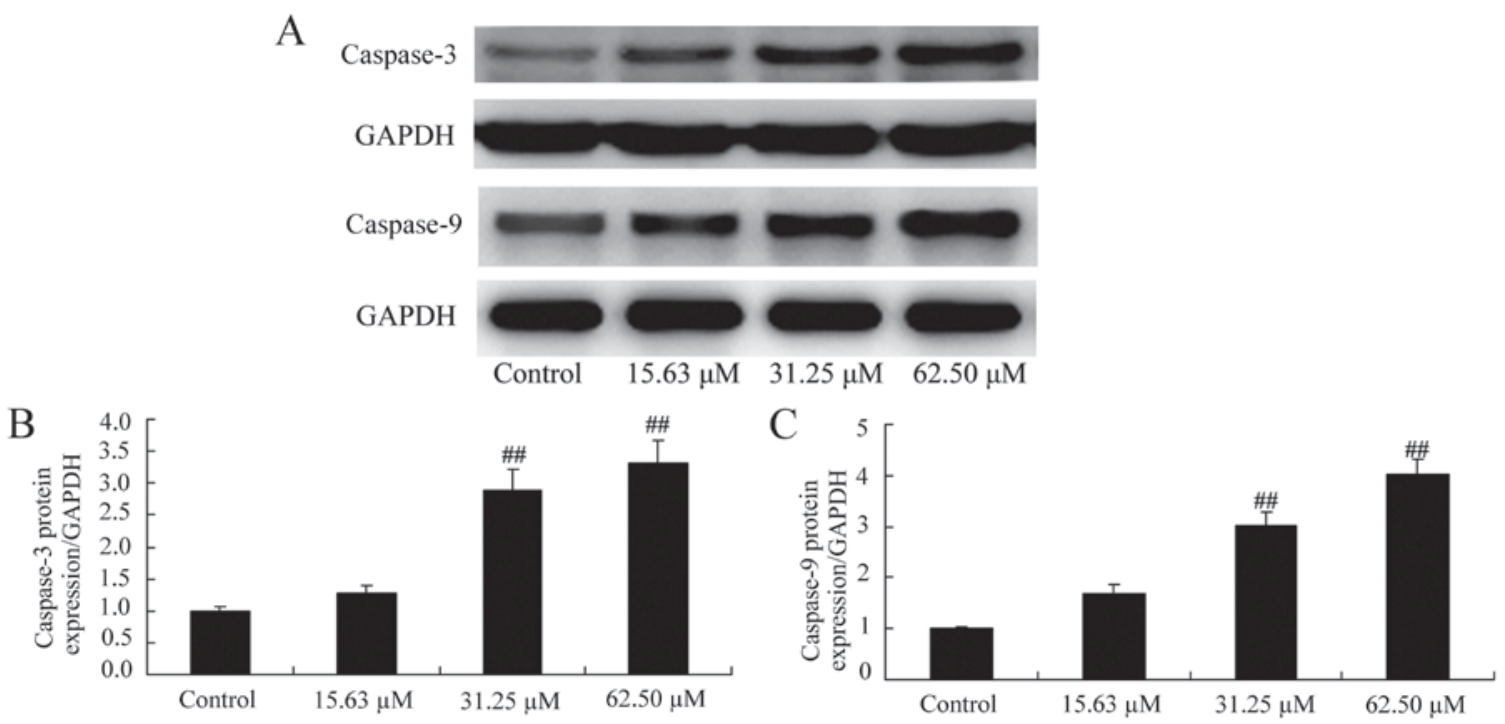

Figure 4. Wogonoside induces caspase-3 and caspase-9 protein expression in LOVO colon cancer cells. (A) Representative blots of caspase-3 and caspase-9 protein expression using western blotting assays, and statistical analysis of (B) caspase-3 and (C) caspase-9 protein expression in LOVO colon cancer cells. ${ }^{\# \#} \mathrm{P}<0.01$ compared with control group.
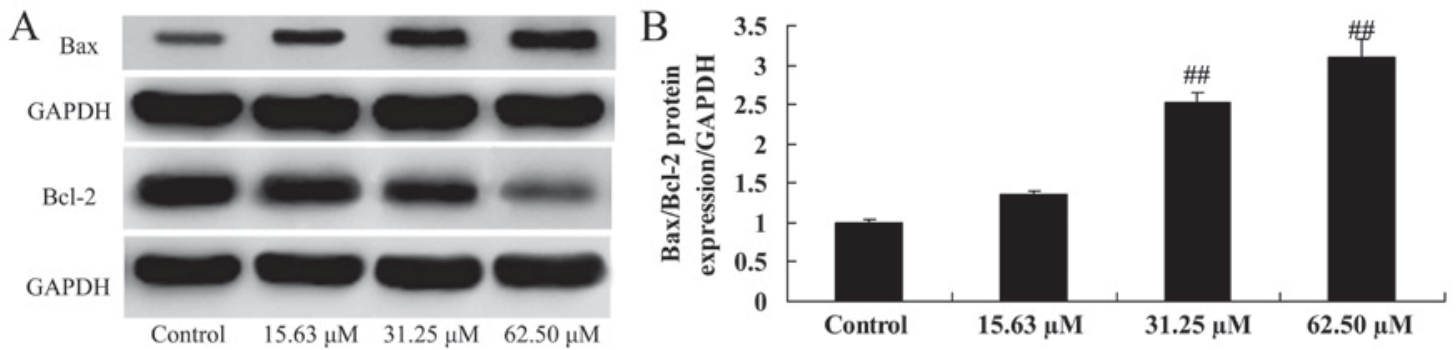

Figure 5. Wogonoside induces Bax/Bcl-2 protein expression in LOVO colon cancer cells. (A) Representative blots of Bax and Bcl-2 protein expression using western blotting assays and (B) statistical analysis of Bax/Bcl-2 protein expression ratio in colon cancer cells. ${ }^{\# /} \mathrm{P}<0.01$ compared with control group. Bax, apoptosis regulator Bax; Bcl-2, apoptosis regulator Bcl-2.

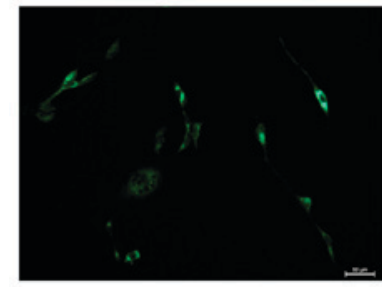

Control

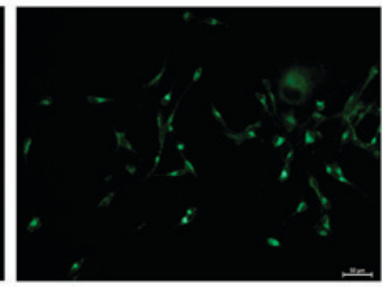

$15.63 \mu \mathrm{M}$

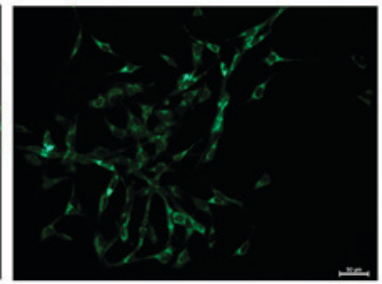

$31.25 \mu \mathrm{M}$

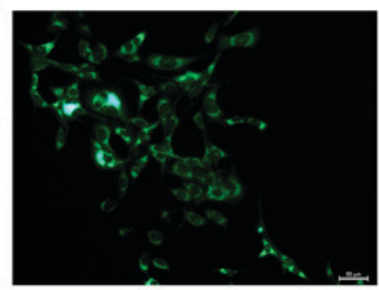

$62.50 \mu \mathrm{M}$

Figure 6. Wogonoside induces mitochondrial-mediated autophagy of colon cancer cells, as demonstrated by immunofluorescence. 
A

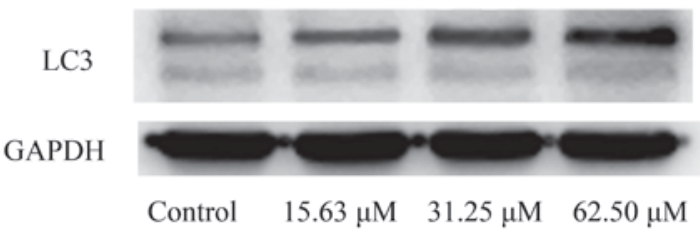

B

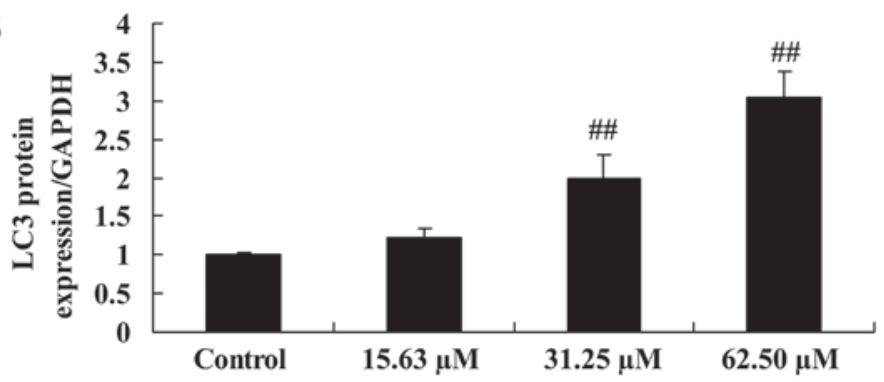

Figure 7. Wogonoside induces LC3 protein expression in LOVO colon cancer cells. (A) Representative blot of LC3 protein expression using western blotting assays and (B) statistical analysis of LC3 protein expression in colon cancer cells. ${ }^{\# \#} \mathrm{P}<0.01$ compared with control group. LC3, microtubule-associated protein 1A/1B-light chain.

A

$$
\text { PI3K }
$$

GAPDH

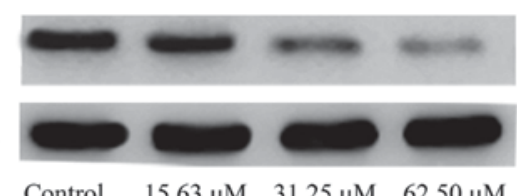

Control $\quad 15.63 \mu \mathrm{M} \quad 31.25 \mu \mathrm{M} \quad 62.50 \mu \mathrm{M}$

$\mathrm{C}$

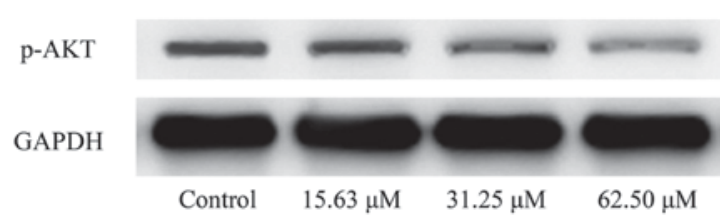

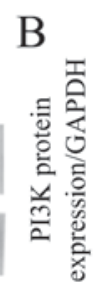
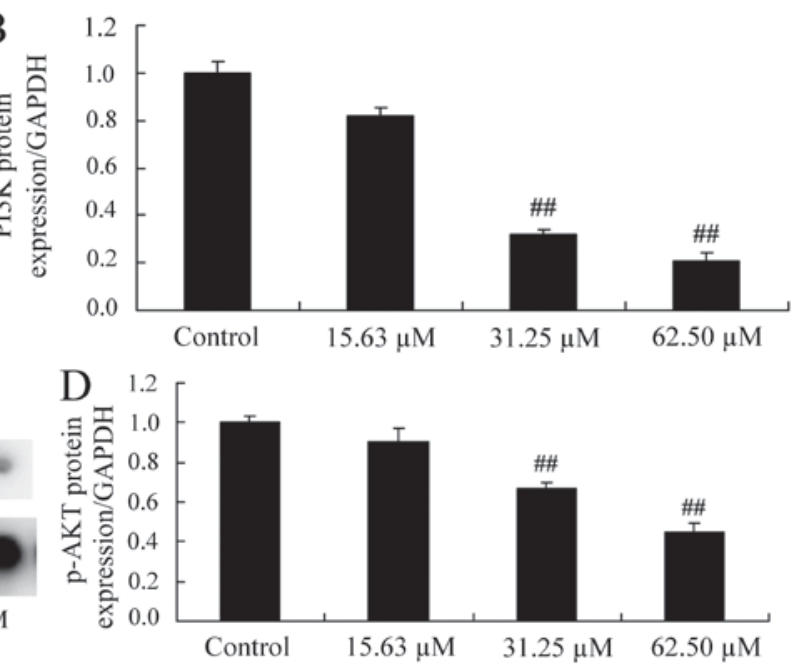

Figure 8. Wogonoside induces PI3K/AKT protein expression in LOVO colon cancer cells. (A) Representative blot and (B) quantification of PI3K protein expression. (C) Representative blot and (D) quantification of p-AKT protein expression using western blotting assays. ${ }^{\sharp \# ~} \mathrm{P}<0.01$ compared with control group. p-, phosphorylated; PI3K, Phosphatidylinositol 3 kinase; AKT, RAC- $\alpha$ serine/threonine-protein kinase.

cells with different concentrations of wogonoside at $48 \mathrm{~h}$. Fig. 7 indicates that wogonoside $(31.25$ or $62.50 \mu \mathrm{M})$ significantly promoted LC3 protein expression in LOVO cells in a dose-dependent manner, compared with the control group.

Wogonoside induces PI3K/AKT protein expression in colon cancer cells. The mechanisms of wogonoside underlying the apoptosis of colon cancer cells via the PI3K/AKT signaling pathway were investigated in LOVO cells. PI3K and p-AKT protein expression was significantly suppressed in LOVO cells treated with 31.25 or $62.50 \mu \mathrm{M}$ of wogonoside in a dose-dependent manner, compared with the control group (Fig. 8).

Wogonoside induces $m$ TOR/p70S6K protein expression in colon cancer cells. The mechanisms of wogonoside underlying the apoptosis of colon cancer cells via the $\mathrm{mTOR} / \mathrm{p} 70 \mathrm{~S} 6 \mathrm{~K}$ signaling pathway were investigated in LOVO cells. Consistently, p-mTOR and p-p70S6K protein expression was significantly suppressed in LOVO cells treated with 31.25 or $62.50 \mu \mathrm{M}$ of wogonoside in a dose-dependent manner, compared with the control group (Fig. 9).

Wogonoside induces p62 protein expression of colon cancer cell. The mechanisms of wogonoside underlying the apoptosis of colon cancer cells via the p62 pathway were investigated in LOVO cells. The results demonstrated that 31.25 or $62.50 \mu \mathrm{M}$ of wogonoside significantly induced p-p62 protein expression in LOVO cells, compared with the control group (Fig. 10).

\section{Discussion}

Autophagy serves an important role in the incidence and development of colon cancer. Autophagy may induce apoptosis and tolerance to nutritional deficiency of colon cancer cells, and elevated autophagy activity may lead to colon cancer (19). Studies have identified that the expression of Atg key proteins, including LC3 and Beclin-1 increase during the early, and advanced stages of colon cancer (7). This may enhance the tolerance of cells located at the tumor core to hypoxia and nutritional deficiency, thus increasing their resistant to cell death (7). In certain cases, the upregulation of autophagy activity may protect colon cancer cells from harm due to chemotherapeutic drugs or selective cell death (20). Therefore, studying the changes in autophagy and autophagy-related genes at the molecular level is of significance to clarify the pathogenesis of colon cancer and identify therapeutic strategies. The present data demonstrated that 

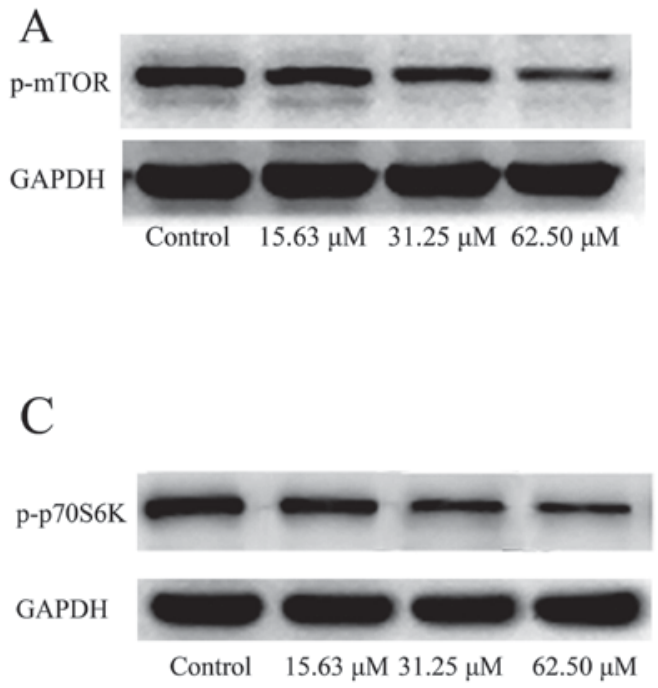
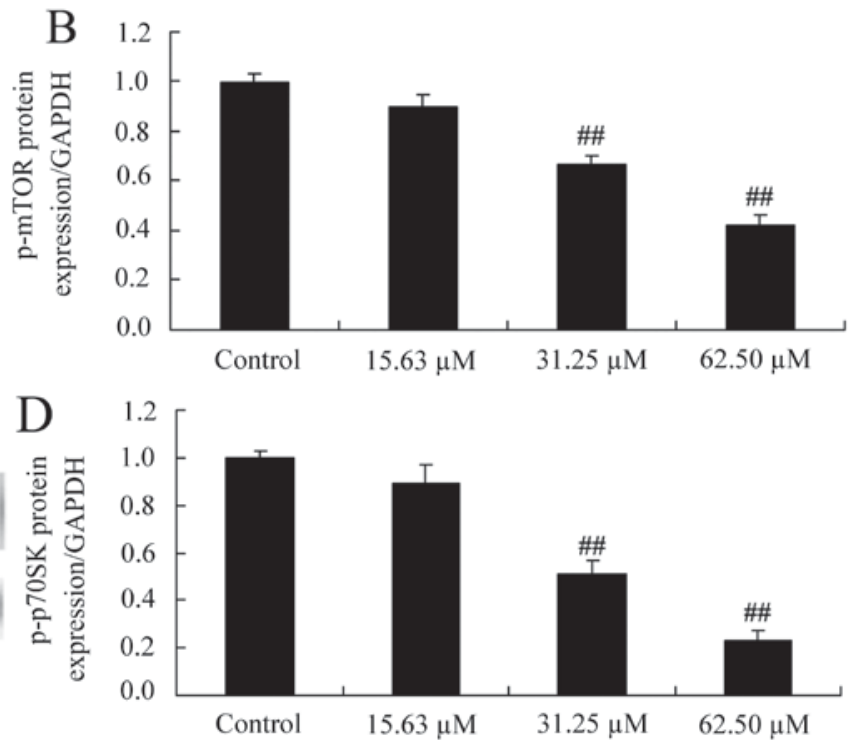

Figure 9. Wogonoside induces mTOR/p70S6K protein expression of colon cancer cells. (A) Representative blot and (B) quantification of p-mTOR protein expression. (C) Representative blot and (D) quantification of p-p70S6K protein expression using western blotting assays. ${ }^{\# \#} \mathrm{P}<0.01$ compared with control group. p, phosphorylated; mTOR, mechanistic target of rapamycin; p70S6K, p70 S6 kinase.
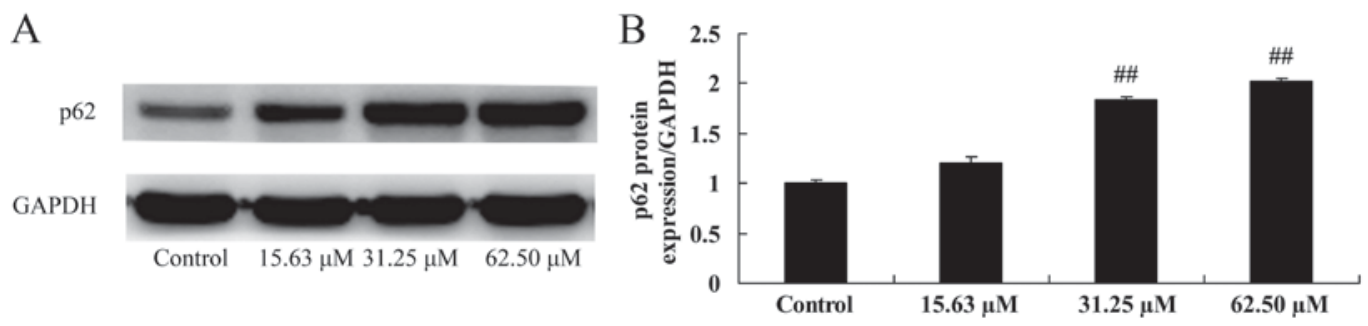

Figure 10. Wogonoside induces p62 protein expression of colon cancer cells. (A) p62 protein expression using western blotting assays and (B) statistical analysis of p62 protein expression in LOVO colon cancer cells. ${ }^{\# \#} \mathrm{P}<0.01$ compared with control group.

wogonoside significantly suppressed cell viability, induced cell apoptosis, and increased caspase-3, caspase-9, LC3 protein expression as well as the $\mathrm{Bax} / \mathrm{Bcl}-2$ ratio in $\mathrm{LOVO}$ cells in a dose-dependent manner. Huang et al (17) demonstrated that wogonoside inhibits angiogenesis via suppressing Wnt $/ \beta$-catenin pathway in breast cancer. Sun et al (21) suggested that wogonoside induces autophagy through regulating the MAPK-mTOR signaling pathway in MDA-MB-231 cells.

ThePI3K/Akt/mTOR signaling pathway serves an important role in the incidence and development of malignant tumors, and drug resistance by inducing the survival, differentiation and angiogenesis of tumor cells, thus, it has become a novel target for the intervention therapy of tumor (22). In numerous malignant tumor types, including breast cancer and non-small cell lung cancer, the PI3K/Akt signaling pathway may prevent the death of cancer cells from chemotherapy or radiotherapy-induced apoptosis (12). Selectively inhibiting PI3K or Akt activity to decrease the phosphorylation of Akt may increase the sensitivity of cells towards apoptosis induced by chemotherapy and radiotherapy (23). For lymphoma with high expression levels of Akt, mTOR inhibitors significantly increase the chemotherapy-induced apoptosis rate of cancer cells (24). In the present study, wogonoside was observed to significantly suppress PI3K and p-AKT protein expression in LOVO cells. Sun et al (25) suggested that wogonoside prevents colitis-associated colorectal carcinogenesis through inhibiting nuclear transcription facto- $\kappa \mathrm{B}(\mathrm{NF}-\kappa \mathrm{B})$ activation via the PI3K/Akt signaling pathway.

Akt is able to regulate multiple genes associated with apoptosis and thereby inhibit cell apoptosis (24). Transcription factor forkhead box O1, a member of the forkhead family, performs numerous activities including the following: Inactivating Akt by translocating it from the nucleus to the cytoplasm; downregulating Fas ligand to induce apoptosis; phosphorylating proapoptotic protein BAD and caspase-9 to inhibit their activity; activating NF- $\mathrm{kB}$ to promote the transcription of apoptosis-inhibiting genes; suppressing the release of cytochrome $\mathrm{C}$; and maintaining the integrity of mitochondria, thereby inhibiting cell death (26). Akt is also able to send survival signals by phosphorylating mTOR, and its downstream molecules, including P70S6K and eukaryotic translation initiation factor $4 \mathrm{E}$-binding protein 1 , thus inhibiting the apoptosis of cells that do not depend on p53 (22). Activated PI3K/Akt may further activate its downstream molecule mTOR through the tuberous sclerosis $1 / 2$ complex. mTOR signaling pathway is essential to cell growth, as activated mTOR signaling pathway inhibits apoptosis induced 
by various stimuli, and promote cell cycle progression and cell survival and proliferation (27). The mTOR signaling pathway not only serves an important role in the growth and proliferation of normal cells, but is also associated with the process whereby normal cells become cancerous, as well as the growth and proliferation of cancer cells (28). In addition, it is involved in angiogenesis, and serves an important role in tumor formation, invasion and metastasis (28). In the present, the results demonstrated that wogonoside significantly suppressed p-mTOR protein expression in LOVO cells. Sun et al (21) suggested that wogonoside induces autophagy through regulating the mitogen-activated protein kinase-mTOR signaling pathway in MDA-MB-231 cells.

P70S6K, the kinase of $40 \mathrm{~S}$ ribosomal small subunit protein $\mathrm{S} 6$ and one of the downstream targets in the $\mathrm{PI} 3 \mathrm{~K} / \mathrm{Akt} / \mathrm{mTOR}$ signaling pathway, directly phosphorylates 40S ribosomal protein S6 to promote the translation of mRNA essential in the Gl-S stage of the cell cycle, as well as the expression of proteins associated with cell growth and differentiation, thus serving an important role in the regulation of cell growth and proliferation $(29,30)$. The mTOR/P70S6K signaling pathway serves an essential role in cell growth, differentiation, proliferation, migration and survival (29). Zhang et al (31) reported wogonoside induces autophagy-related apoptosis in human glioblastoma cells through the PI3K/AKT/mTOR/p70S6K signaling pathway.

In conclusion, the present study demonstrated that wogonoside significantly inhibits cell growth, induces apoptosis and mitochondrial-mediated autophagy of colon cancer cells, which is regulated by the $\mathrm{PI} 3 \mathrm{~K} / \mathrm{AKT} / \mathrm{mTOR} / \mathrm{p} 70 \mathrm{~S} 6 \mathrm{~K}$ pathway. Therefore, these findings provide a basis for future investigations aimed at elucidating the anticancer effect of wogonoside on apoptosis and autophagy in colon cancer therapy.

\section{Acknowledgements}

The present study was supported by the Natural Science Foundation of the Institutions of Higher Education from the Education Department of Anhui Province (grant no. KJ2017A261) and Natural Science Foundation of Wannan Medical College (grant no. WK2016F08).

\section{References}

1. Liu C, Huang $\mathrm{Z}$, Jiang $\mathrm{H}$ and Shi $\mathrm{F}$ : The sirtuin 3 expression profile is associated with pathological and clinical outcomes in colon cancer patients. Biomed Res Int 2014: 871263, 2014.

2. Chen WK, Ren L, Wei Y, Zhu DX, Miao CH and Xu JM: General anesthesia combined with epidural anesthesia ameliorates the effect of fast-track surgery by mitigating immunosuppression and facilitating intestinal functional recovery in colon cancer patients. Int J Colorectal Dis 30: 475-481, 2015.

3. Declercq J, Jacobs B, Biesmans B, Roth A, Klingbiel D, Tejpar S and Creemers JW: Single nucleotide polymorphism (rs4932178) in the P1 promoter of FURIN is not prognostic to colon cancer. Biomed Res Int 2015: 321276, 2015.

4. Hestetun KE, Brydøy M, Myklebust MP and Dahl O: Nuclear maspin expression as a predictive marker for fluorouracil treatment response in colon cancer. Acta Oncol 54: 470-479, 2015.

5. Kumar A, Singh B, Sharma PR, Bharate SB, Saxena AK and Mondhe DM: A novel microtubule depolymerizing colchicine analogue triggers apoptosis and autophagy in HCT-116 colon cancer cells. Cell Biochem Funct 34: 69-81, 2016.
6. Buchser WJ, Laskow TC, Pavlik PJ, Lin HM and Lotze MT: Cell-mediated autophagy promotes cancer cell survival. Cancer Res 72: 2970-2979, 2012.

7. Wu S, Wang X, Chen J and Chen Y: Autophagy of cancer stem cells is involved with chemoresistance of colon cancer cells. Biochem Biophys Res Commun 434: 898-903, 2013.

8. Coker-Gürkan A, Arisan ED, Obakan P, Akalin K, Özbey U and Palavan-Unsal N: Purvalanol induces endoplasmic reticulum stress-mediated apoptosis and autophagy in a time-dependent manner in HCT116 colon cancer cells. Oncol Rep 33: 2761-2770, 2015.

9. Park JM, Huang S, Wu TT, Foster NR and Sinicrope FA: Prognostic impact of Beclin 1, p62/sequestosome 1 and LC3 protein expression in colon carcinomas from patients receiving 5-fluorouracil as adjuvant chemotherapy. Cancer Biol Ther 14: 100-107, 2013.

10. Xiong HY, Guo XL, Bu XX, Zhang SS, Ma NN, Song JR, Hu F, Tao SF, Sun K, Li R, et al: Autophagic cell death induced by 5-FU in Bax or PUMA deficient human colon cancer cell. Cancer Lett 288: 68-74, 2010.

11. Zou H, Li L, Garcia Carcedo I, Xu ZP, Monteiro M and $\mathrm{Gu}$ W: Synergistic inhibition of colon cancer cell growth with nanoemulsion-loaded paclitaxel and PI3K/mTOR dual inhibitor BEZ235 through apoptosis. Int J Nanomedicine 11: 1947-1958, 2016.

12. Zhu L, Derijard B, Chakrabandhu K, Wang BS, Chen HZ and Hueber AO: Synergism of PI3K/Akt inhibition and Fas activation on colon cancer cell death. Cancer Lett 354: 355-364, 2014.

13. Wang ZG, Wang Y, Huang Y, Lu Q, Zheng L, Hu D, Feng WK, Liu YL, Ji KT, Zhang HY, et al: bFGF regulates autophagy and ubiquitinated protein accumulation induced by myocardial ischemia/reperfusion via the activation of the PI3K/Akt/mTOR pathway. Sci Rep 5: 9287, 2015.

14. Cao ZX, Yang YT, Yu S, Li YZ, Wang WW, Huang J, Xie XF, Xiong L, Lei S and Peng C: Pogostone induces autophagy and apoptosis involving PI3K/Akt/mTOR axis in human colorectal carcinoma HCT116 cells. J Ethnopharmacol 202: 20-27, 2016.

15. Cai Y, Li S, Li T, Zhou R, Wai AT and Yan R: Oral pharmacokinetics of baicalin, wogonoside, oroxylin A 7-O-beta-d-glucuronide and their aglycones from an aqueous extract of Scutellariae Radix in the rat. J Chromatogr B Analyt Technol Biomed Life Sci 1026: 124-133, 2016.

16. Yang YZ, Tang YZ and Liu YH: Wogonoside displays anti-inflammatory effects through modulating inflammatory mediator expression using RAW264.7 cells. J Ethnopharmacol 148: 271-276, 2013.

17. Huang Y, Zhao K, Hu Y, Zhou Y, Luo X, Li X, Wei L, Li Z, You Q, Guo Q and Lu N: Wogonoside inhibits angiogenesis in breast cancer via suppressing Wnt/ $\beta$-catenin pathway. Mol Carcinog 55: 1598-1612, 2016.

18. Yu C, Zhang Z, Zhang H, Zhen Z, Calway T, Wang Y, Yuan CS and Wang CZ: Pretreatment of baicalin and wogonoside with glycoside hydrolase: A promising approach to enhance anticancer potential. Oncol Rep 30: 2411-2418, 2013.

19. Pigna E, Berardi E, Aulino P, Rizzuto E, Zampieri S, Carraro U, Kern H, Merigliano S, Gruppo M, Mericskay M, et al: Aerobic exercise and pharmacological treatments counteract cachexia by modulating autophagy in colon cancer. Sci Rep 6: 26991, 2016.

20. Kwatra D, Subramaniam D, Ramamoorthy P, Standing D, Moran E, Velayutham R, Mitra A, Umar S and Anant S: Methanolic extracts of bitter melon inhibit colon cancer stem cells by affecting energy homeostasis and autophagy. Evid Based Complement Alternat Med 2013: 702869, 2013.

21. Sun Y, Zou M, Hu C, Qin Y, Song X, Lu N and Guo Q: Wogonoside induces autophagy in MDA-MB-231 cells by regulating MAPK-mTOR pathway. Food Chem Toxicol 51: 53-60, 2013.

22. Zhang LL, Mu GG, Ding QS, Li YX, Shi YB, Dai JF and Yu HG: Phosphatase and Tensin Homolog (PTEN) represses colon cancer progression through inhibiting paxillin transcription via PI3K/AKT/NF-kappaB pathway. J Biol Chem 290: 15018-15029, 2015.

23. Tahir AA, Sani NF, Murad NA, Makpol S, Ngah WZ and Yusof YA: Combined ginger extract \& Gelam honey modulate Ras/ERK and PI3K/AKT pathway genes in colon cancer HT29 cells. Nutr J 14: 31, 2015. 
24. Meng $\mathrm{Y}$, Lin ZM, Ge N, Zhang DL, Huang $\mathrm{J}$ and Kong $\mathrm{F}$ : Ursolic acid induces apoptosis of prostate cancer cells via the PI3K/Akt/mTOR pathway. Am J Chin Med 43: 1471-1486, 2015.

25. Sun Y, Zhao Y, Wang X, Zhao L, Li W, Ding Y, Kong L, Guo Q and $\mathrm{Lu} \mathrm{N}$ : Wogonoside prevents colitis-associated colorectal carcinogenesis and colon cancer progression in inflammation-related microenvironment via inhibiting $\mathrm{NF}-\kappa \mathrm{B}$ activation through PI3K/Akt pathway. Oncotarget 7: 34300-34315, 2016.

26. Pal I and Mandal M: PI3K and Akt as molecular targets for cancer therapy: Current clinical outcomes. Acta Pharmacol Sin 33: 1441-1458, 2012.

27. Gulhati P, Bowen KA, Liu J, Stevens PD, Rychahou PG, Chen M, Lee EY, Weiss HL, O'Connor KL, Gao T and Evers BM: mTORC1 and mTORC2 regulate EMT, motility, and metastasis of colorectal cancer via RhoA and Racl signaling pathways. Cancer Res 71: 3246-3256, 2011.
28. Qazi AK, Hussain A, Khan S, Aga MA, Behl A, Ali S, Singh SK, Taneja SC, Shah BA, Saxena AK, et al: Quinazoline based small molecule exerts potent tumour suppressive properties by inhibiting PI3K/Akt/FoxO3a signalling in experimental colon cancer. Cancer Lett 359: 47-56, 2015.

29. Gu S, Kounenidakis M, Schmidt EM, Deshpande D, Alkahtani S, Alarifi S, Föller M, Alevizopoulos K, Lang F and Stournaras C: Rapid activation of FAK/mTOR/p70S6K/PAK1-signaling controls the early testosterone-induced actin reorganization in colon cancer cells. Cell Signal 25: 66-73, 2013 .

30. Xu Q, Liu LZ, Qian X, Chen Q, Jiang Y, Li D, Lai L and Jiang BH: MiR-145 directly targets p70S6K1 in cancer cells to inhibit tumor growth and angiogenesis. Nucleic Acids Res 40: 761-774, 2012.

31. Zhang L, Wang H, Cong Z, Xu J, Zhu J, Ji X and Ding K: Wogonoside induces autophagy-related apoptosis in human glioblastoma cells. Oncol Rep 32: 1179-1187, 2014. 